\title{
Statement on methods in sport injury research from the 1st METHODS MATTER Meeting, Copenhagen, 2019
}

\author{
Rasmus Oestergaard Nielsen (D) , 1,2 Ian Shrier, $^{3}$ Marti Casals (D) ,,5 \\ Albertro Nettel-Aguirre, ${ }^{6}$ Merete Møller (D) , ${ }^{7}$ Caroline Bolling, ${ }^{8}$ \\ Natália Franco Netto Bittencourt, ${ }^{8,9,10}$ Benjamin Clarsen (D) , 11,12 \\ Niels Wedderkopp, ${ }^{13,14}$ Torbjørn Soligard (D) , ${ }^{15}$ Toomas Timpka (D) , 16 \\ Carolyn Emery (D) ,' Roald Bahr, ${ }^{12}$ Jenny Jacobsson (D) , 18 \\ Rod Whiteley (D) ,' ${ }^{19}$ Orjan Dahlstrom (D) , ${ }^{20}$ Nicol van Dyk, ${ }^{21}$ \\ Babette M Pluim, ${ }^{8,22,23}$ Emmanuel Stamatakis (D) , 24,25 \\ Luz Palacios-Derflingher, ${ }^{26}$ Morten Wang Fagerland, ${ }^{12}$ \\ Karim M Khan (D) , ${ }^{27,28}$ Clare L Ardern (D) , ${ }^{29,30}$ Evert Verhagen
}

\begin{abstract}
High quality sports injury research can facilitate sports injury prevention and treatment. There is scope to improve how our field applies best practice methods - methods matter (greatly!). The 1st METHODS MATTER Meeting, held in January 2019 in Copenhagen, Denmark, was the forum for an international group of researchers with expertise in research methods to discuss sports injury methods. We discussed important epidemiological and statistical topics within the field of sports injury research. With this opinion document, we provide the main take-home messages that emerged from the meeting.
\end{abstract}

\section{OPINIONS FROM THE MEETING}

Meeting participants agreed that the definition of sports injury depends on the research question and context. It was considered essential to be explicit about the goal of the research effort and to use frameworks to illustrate the assumptions that underpin measurement and the analytical strategy. Complex systems were discussed to illustrate how potential risk factors can interact in a non-linear way. This approach is often a useful alternative to identifying single risk factors. Investigating changes in exposure status over time is important when analysing sport injury aetiology, and analysing recurrent injury, subsequent injury or injury exacerbation remains challenging. The choice of statistical model should consider the research question, injury measure (eg,

For numbered affiliations see end of article.

Correspondence to Dr Rasmus Oestergaard Nielsen, Department of Public Health, Section for Sports Science, Aarhus University, Aarhus 8000, Denmark; roen@ph.au.dk prevalence, incidence), type and granularity of injury data (categorical or continuous) and study design.

\section{THE FUTURE}

Multidisciplinary collaboration will be a cornerstone for future high-quality sports injury research. Working outside professional silos in a diverse, multidisciplinary team benefits the research process from the formulation of research questions and designs to the statistical analyses and dissemination of study results in implementation contexts.

This article has been co-published in the British Journal of Sports Medicine and the Journal of Orthopaedic \& Sports Physical Therapy.

\section{INTRODUCTION}

Sports injury researchers have powerful statistical software packages at their disposal to help answer increasingly sophisticated questions posed by coaches, clinicians and athletes. New statistical approaches, aetiological and causal frameworks, and complex systems theory continue to be developed and refined-a gift and a challenge in equal measure. This ongoing development of methodological approaches allows for high-quality analyses that advance the broad field of sports injury research to improve clinical care, injury treatment and injury prevention. ${ }^{1}$

Two decades ago, in general medical journals, the proportion of published articles with questionable application of statistical methods reportedly ranged from $39 \%$ to $90 \% .^{2}$ Researchers made so many basic statistical errors that the late Professor Douglas Altman, a former Director of the Centre for Statistics in
Medicine in Oxford, declared that the level of inappropriate use of statistical techniques in biomedical research was a scandal. ${ }^{3}$ In the future, it is therefore essential that similar or even worse findings than those in biomedical research two decades ago are not repeated in the present sports injury research context. After all, methods matter! ${ }^{1}$

"How often do we discuss epidemiology, causality and statistical sciences in sports injury research?", you may ask. To the best of our knowledge, no specific community or forum exists on epidemiology or statistics in sports injury research. Training new researchers to conduct methodologically robust sports injury research is often limited and inadequate, and researchers-both experienced and inexperienced-often employ traditional methods that may not be ideal for their type of data and research question. This limited focus on methodology inspired the first METHODS MATTER Meeting for a group of representative researchers. The goal was to discuss epidemiological and statistical topics within the field of sports injury research. With this opinion document, we provide readers of sports injury research with a summary of discussions and the main take-home messages that emerged from the 1st METHODS MATTER Meeting. An overview of these take-home messages is provided in table 1 .

\section{METHODS}

The 1st METHODS MATTER Meeting was held in Copenhagen, Denmark on 29 and 30 January 2019. Thirty-one researchers from 13 countries were invited and 25 researchers from 11 countries attended. The agenda consisted of six pre-selected topics: (1) injury definition; (2) sports injury data and statistical modelling; (3) complex systems thinking and computational modelling; (4) longitudinal data analyses; (5) recurrent and subsequent injuries; and (6) causality.

In each session, the key elements were introduced by two or three presentations, after which a discussion followed on the content of the presentations and other topics that emerged (for the meeting invitation, title of presentations and book of abstracts see the online supplementary file). Each session-specific discussion was guided by a scientific facilitator and a moderator. The facilitator was a content expert who ensured that everyone had a chance to contribute to the discussion. The facilitator encouraged discussions around the table and aimed to provide a 
Table 1 Take-home messages and recommendations from the 1st Methods Matter Meeting

\begin{tabular}{|c|c|}
\hline Topic & Opinions and recommendations \\
\hline $\begin{array}{l}\text { No universal sports injury definition is } \\
\text { necessary }\end{array}$ & $\begin{array}{l}\text { 1. There is no need for a single universally accepted definition of sports injury } \\
\text { 2. Choosing an injury definition is a balancing act between a range of factors, such as level of pain/injury severity, number of cases, } \\
\text { research question and ease of reporting. As these factors are often competing, we encourage researchers to match their choice of } \\
\text { definition to the study purpose, setting and design }\end{array}$ \\
\hline $\begin{array}{l}\text { Be explicit about the goal of your } \\
\text { research: are you describing, predicting } \\
\text { or drawing a causal inference? }\end{array}$ & $\begin{array}{l}\text { 3. Be explicit about the research goal (eg, description, prediction or causal inference) } \\
\text { 4. To ensure that sports injury researchers report the goal of their research in their publications, we recommend coordinated action } \\
\text { by sports science and medicine journals. For instance, the author guidelines could state that authors should explicitly describe their } \\
\text { research goal } \\
\text { 5. Define the terms used in research (eg, prediction, causation). Standard language that clinicians and researchers understand will } \\
\text { improve evidence transparency and quality }\end{array}$ \\
\hline Frameworks can guide researchers & $\begin{array}{l}\text { 6. Clearly outline your assumptions. Specifying your theoretical framework and/or drawing a causal diagram when dealing with a } \\
\text { causal question is generally very helpful to the reader }\end{array}$ \\
\hline Analysing longitudinal data & $\begin{array}{l}\text { 7. As sports injury occurrence is likely a highly dynamic process, investigating changes over time is important. Consequently, sports } \\
\text { injury researchers are recommended to embrace the options that longitudinal data offer }\end{array}$ \\
\hline $\begin{array}{l}\text { Which statistical approach should I } \\
\text { choose? }\end{array}$ & $\begin{array}{l}\text { 8. The choice of the statistical analytical approach depends on various factors including, but not limited to, research question, injury } \\
\text { measure (eg, prevalence, incidence), type of injury data (categorical or numerical/continuous) and study design }\end{array}$ \\
\hline $\begin{array}{l}\text { Sports injuries are complex and } \\
\text { contextual }\end{array}$ & $\begin{array}{l}\text { 12. Researchers require at least a basic understanding of what complex systems entail and how to interpret the results to better use } \\
\text { complex system analysis in sports science } \\
\text { 13. Statistical modelling and systems-based modelling approaches that recognise non-linear complex interactions complement } \\
\text { traditional biostatistical and epidemiological methods } \\
\text { 11. Approaches that combine qualitative and quantitative methods may help investigators better understand how non-linear complex } \\
\text { interactions underpin most sports injuries }\end{array}$ \\
\hline $\begin{array}{l}\text { Need for multidisciplinary teams and } \\
\text { collaborations }\end{array}$ & $\begin{array}{l}\text { 15. Collaboration bridges gaps between statisticians, epidemiologists, sports injury researchers, athletes and clinical experts } \\
\text { 16. Involve statisticians, epidemiologists and practitioners early when designing a study, not after data have been collected } \\
\text { 17. Working in diverse multidisciplinary teams should help to better formulate research questions, identify an appropriate study design, } \\
\text { ensure appropriate and legally acceptable data acquisition, conduct correct statistical analyses, make proper interpretation of study } \\
\text { results and disseminate them in suitable implementation contexts } \\
\text { 12. Stakeholders in sports injury research are encouraged to intensify their investments in statistical, epidemiological and } \\
\text { methodological education in our field, such as multisite and interdisciplinary collaborations, training reviewers, providing online } \\
\text { opportunities, exchanging trainees, developing (and extending) guidelines and including methods content in regular scientific } \\
\text { meetings }\end{array}$ \\
\hline
\end{tabular}

concise 2-minute summary at the end of each session. The moderator kept time.

After the meeting, each facilitator drafted a summary of their session and this was circulated to the presenters and moderator associated with that topic for review. Authors RON and EV merged the six documents and drafted the introduction, methods and conclusion, which were then distributed to all authors for a first round of feedback. After revisions, the full-text manuscript was circulated twice for final comments and suggestions for improvement prior to submission.

The attendees agreed on certain issues (eg, an injury definition depends on a range of factors) and were challenged by other issues (eg, how to best analyse recurrent events). Consequently, this manuscript should not be regarded as a consensus statement. We hope it will serve as a tool for sports science researchers dealing with the complexity of sports injury epidemiology, causality, sports biostatistics and other methodological issues.
Our views and take-home messages are presented under the following eight headings: (1) No universal sports injury definition is necessary. (2) Be explicit about the goal of your research: are you describing, predicting or drawing a causal inference? (3) Frameworks can guide researchers. (4) Analysing longitudinal data. (5) Which statistical model should I choose? (6) Dealing with recurrent or subsequent injury. (7) Complex systems. (8) Need for multidisciplinary collaborations.

\section{NO UNIVERSAL SPORTS INJURY DEFINITION IS NECESSARY}

Injury consensus statements across sports use different definitions of sport injury, ${ }^{4-12}$ in part because the definition depends on the context. ${ }^{13-15}$ Researchers planning a sports injury study need to consider a range of operational injury definitions. These can be roughly divided into broad categories with respect to time loss from sports, such as 'any physical complaint', which includes non-time loss injuries, and more narrow definitions (eg, 'unavailable for competition'). Studies that use a broader definition often have greater statistical power because more injuries are captured. However, collecting detailed injury data using a broad definition may be resource-demanding, require criteria that are more subjective, and capture a number of injuries with minimal consequences (eg, cuts and bruises). In contrast, narrow definitions are generally based on more objective criteria and filter out less severe cases. Associations may exist for a broader definition when none exist for a narrow definition, or vice versa.

Traditionally, measures such as prevalence proportion or incidence rate are reported in sports injury studies. ${ }^{16}$ At the METHODS MATTER Meeting, we discussed the outcomes 'injury severity' and 'injury burden'. ${ }^{17} 18$ Currently, there is no consensus on the definition of injury burden or on how to operationalise burden in statistical analyses. Creating a composite burden score (eg, 
the severity score from the Oslo Sports Trauma Research Centre questionnaire) from different outcome measures to collapse a complex phenomenon into one number should be considered with caution. This approach risks omitting important information (eg, the difference between prevention and treatment). Still, the idea of injury burden is appealing, as it aims to provide more information on the consequences of an injury beyond the classical measures of prevalence and incidence.

Recording sports injury events in practice is also contingent on who identifies the event (ie, whether it is researchers, athletes, coaches and managers, clinicians or combinations of these). For instance, loyalty or toughness may encourage athletes, coaches and medical staff to downplay injury symptoms or hasten return-to-sport.

The choice of sports injury definition should also be guided by the research question. For example, studies of workload and injury risk have typically recorded only non-contact injuries, based on an assumption that workload is unrelated to contact injuries. ${ }^{19}$ On the other hand, studies of overuse injuries in general require broad definitions, as athletes often continue to participate in training and competition despite being injured. ${ }^{20}{ }^{21} \mathrm{In}$ addition, we need to consider how to capture a sports injury when it originates from sport, from an activity of daily living or from a combination of the two. A continued discussion on these (and other) aspects related to injury definitions is needed.

\section{BE EXPLICIT ABOUT THE GOAL OF YOUR RESEARCH: ARE YOU DESCRIBING, PREDICTING OR DRAWING A CAUSAL INFERENCE?}

In causal inference, “... being explicit about the goal of the analysis is a prerequisite for good science", 22 and we recommend the practice for sports injury researchers as well. For such clarification, a 3-fold classification of the research goal, which was published recently, ${ }^{23}$ may be used:

1. Description: for instance, describe injury risk or rate over time in a group of athletes.

2. Prediction: for instance, examine which athletes are more likely to sustain injury than others; in plain language, this translates to identifying/ predicting 'who' is at high risk of getting injured.

3. Causal inference: for instance, examine the causal effect of an exposure on sports injury; in layman's terms, this translates to examining 'why' or 'how' an injury occurs using intrinsic and extrinsic causes of injury.

When identifying the research goal, it is important to understand that every true causal factor (if it is well measured) is a predictor (although sometimes a weak one), but not every predictor is a causal factor. ${ }^{24} 25$ As an example, American football players wearing a shirt with an animal logo had a lower risk of concussion than players who wore shirts without an animal logo. ${ }^{26}$ Here, the 'who' question (prediction) was addressed through an animal logo variable that is not a causal factor (most likely, changing one's jersey will not change risk of concussion).

If the sports injury researcher is aiming to investigate the causal effect of body weight (or another causal question) on sports injury occurrence, he or she is dealing with a 'why' question. In this case, concepts such as confounding, effect-measure modification, and mediation should be given careful attention and consideration, as the aetiology of sports injury is likely to be multifactorial. ${ }^{27}$ If the goal is prediction, attention to subgroup differences may be needed, depending on the research question of interest.

At the METHODS MATTER Meeting, there was discussion about whether the terms 'why' and 'how' cover the same concept. We did not reach agreement. Clinicians, coaches and athletes should be aware that some sports injury researchers use the 'why' and 'how' terms interchangeably. Some may consider 'why' and 'how' to cover different aspects (eg, aetiology and mechanisms, respectively), ${ }^{28}$ and others may avoid using the terms altogether.

\section{FRAMEWORKS CAN GUIDE RESEARCHERS}

Researchers should be encouraged to disclose the underlying assumptions of their analyses. Sports injury frameworks help to illustrate the assumptions underpinning 'who' or 'why'-related questions. The fundamental rationale and theoretical basis that a sports injury occurs if the load applied to a body structure exceeds its capacity to withstand the $\operatorname{load}^{29}$ led to different frameworks about the causal relationship between workload and injury, with slightly different assumptions. ${ }^{28} 30-33$ For example, a dynamic model of aetiology in sport injury was presented in 2007 , in which the authors argued that "exposure is a combination of both possessing a risk factor and then participating (to a greater or lesser degree) with the risk factor". ${ }^{34}$

In a sports injury setting, if the aim is to assess causality, directed acyclic graphs (DAGs) and other causal diagrams can help illustrate which variables to include and adjust for in a statistical analysis. It has been recommended that sports injury researchers include DAGs in their publications. ${ }^{35} 36$ Directed acyclic graphs are useful to understand when to adjust for confounding variables, ${ }^{3738}$ when an effect is mediated through another variable, and when adjusting for a variable introduces new bias rather than minimising bias. This is important when trying to investigate the average/direct/indirect/total causal effect of a certain causal factor in sports injury occurrence. ${ }^{39}{ }^{40}$ For additional information on DAGs, we refer readers to other published literature. ${ }^{35}$

\section{ANALYSING LONGITUDINAL DATA}

Longitudinal data may be viewed as multiple records (eg, injury status) on one or more athletes over time. New technologies make access to such data easier, but they carry the price of in-depth considerations when analysing the data. ${ }^{41}$ Irrespective of the size of the data set, researchers must ensure that they collect appropriate data (in an appropriate manner) to answer specific and clear research questions, and that they employ correct statistical tools to handle such data. ${ }^{42}$ Athletes often change their training schedule and characteristics. In the 1970s, general methodologists of science insisted that it was impossible to measure how health-related exposures and outcomes changed over time. ${ }^{43}$ Researchers interested in the study of change were encouraged to frame their questions in other ways. ${ }^{43}$ Later, this was identified as poor advice. ${ }^{43}$

As sports injury occurrence is a highly dynamic process, ${ }^{27}$ investigating changes over time is important. Consequently, sports injury researchers are recommended to embrace the options that longitudinal data offer. For instance, longitudinal data permit the calculation of metrics that quantify absolute or relative changes in training load. ${ }^{44} 45$ When studying change over time, time-varying exposures (eg, change in training load) and time-varying outcomes (eg, change in injury status) are two essential concepts. ${ }^{46}$ The open question remains: Which approach is suitable for which question and data? There are many options (eg, time-toevent methods, ${ }^{45}$ g-methods, ${ }^{47}$ survival trees ${ }^{48}$ classification and regression trees 
with repeated events, ${ }^{49}$ and generalised linear mixed models ${ }^{50}$ ). The most suitable approach for the research question should be given greater consideration in sports injury research in the future. At best, sports injury epidemiologists and sports biostatisticians should be included when deciding on the analytical approach. ${ }^{42}$

Although the advantage of large-scale longitudinal data must be highlighted, these data also carry challenges, including (1) handling dependencies in these data due to the repeated measures on each individual; (2) missing data, which are often substantial in these studies; (3) censoring; ${ }^{45}$ (4) competing risk; ${ }^{44}$ and (5) understanding the complexity of the statistical analyses required to take full advantage of the many opportunities longitudinal data provide. Ignoring these challenges when fitting models may lead to biased estimates and misinterpretation of results. ${ }^{42} 44-46$

\section{WHICH STATISTICAL APPROACH SHOULD I CHOOSE?}

Injury data are often classified as a dichotomous outcome (ie, an athlete is either injured or not injured) or as different categorical states that each athlete can inhabit over time. However, other ways of collecting and handling injury data exist, as (1) athletes often move between various states of injury severity, (2) athletes can have more than one injury or (3) researchers are interested in other injury-related outcomes. This reality may be better reflected in injury data of greater detail and granularity, which can end up being categorical or numerical. ${ }^{44}$ The type and granularity of injury data has a substantial impact when choosing the statistical approach. For instance, logbinomial regression or logistic regression requires a dichotomous injury outcome, whereas linear regression requires numerical/continuous data. In addition to the type of injury data, the type of injury outcome measures (eg, prevalence proportion or incidence rate) also has implications when choosing statistical models as well.

Different statistical approaches continue to be integrated in the field, including data imputation, time-to-event analysis, longitudinal data and clustered data, among others. Machine learning approaches to data, of which prediction is the main goal, are also being considered. ${ }^{235152}$ Whether the analyses of interest are descriptive or inferential (the latter can be subdivided into prediction or causal inference), authors should use appropriate terms, concepts and methods accordingly. ${ }^{25}$ Study design and outcomes of interest will play an important role in deciding the appropriate analytical approaches beyond the classical regression techniques.

A common analytical approach is the generalised linear model. ${ }^{53}$ This approach requires independence between observations of the injury outcome. However, these assumptions may be violated in some situations, such as clustered studies (outcomes of individuals within a cluster may be more similar than those of individuals between clusters) or longitudinal studies (repeated measures of the same athletes are analogous to clustering in an individual). Ignoring non-independence of data when fitting the model may lead to incorrect estimation of standard errors and erroneous conclusions often due to overstated statistical significance. The two following techniques are often used to account for correlated data of any type: (1) adding a 'random effect' to account for clustering (eg, generalised linear mixed models, frailty models), or (2) incorporating a correlation structure for the observations (eg, generalised estimating equations (GEE)).

There is a special interest in recurrent event data. The simplest approach to analysis in this setting is to count the events observed within a given period. These counts are usually assumed to follow a Poisson distribution. ${ }^{54}$ Where the variance of the counts (rates) is not the same as the mean (ie, data do not follow a Poisson distribution), a quasi-Poisson or a negative binomial distribution is an alternative choice. ${ }^{55}{ }^{56}$ Another way of looking at recurrent event data is to model the time to event. In this case, the time to event of all individuals may not be fully observed, as this may be subject to censoring (eg, drop out from the study before complete follow-up).

Analysing data in a 'competing risk' setting (when other outcomes may preclude the outcome of primary interest and/or change the probability of the outcome of interest) may be important, as athletes may sustain multiple injuries over time. ${ }^{4457}$ Some suggested methods to analyse data in the face of these challenges include competing risk models, ${ }^{445}$ multistate models ${ }^{57}$ and recurrent event models with a time-dependent covariate. ${ }^{58-60}$

\section{DEALING WITH RECURRENT OR SUBSEQUENT INJURY}

There is wide recognition that a subsequent injury can be correlated to a previous injury. When analysing subsequent injury, the terms 'repeat', 'recurrent', 'exacerbation' or 'multiple' are often used interchangeably. To avoid confusion, authors should clearly define their terminology in each manuscript. For example, the answer to "when is an injury considered healed?" depends on the research question, and multistate models might provide a framework for researchers and clinicians to help decide on the appropriate categorisation. ${ }^{61}$ Importantly, models and frameworks should be transparent, valid and demonstrate clinical utility for the end user. Here, valid and reliable assessment of injury data over time is important. Momentary assessment was discussed as a tool to record information on recurrent injury, including occurrence day and recovery day (however defined). ${ }^{62-67}$

Competing risks and analysis of recurrent events are major challenges in sports injury research, ${ }^{5768-70}$ and there is considerable uncertainty about how to handle these. Methods like the Aalen-Johansen estimator could be a useful alternative to the Kaplan-Meier estimator in survival analyses when dealing with competing risks. ${ }^{44}$ Extra precaution should be taken when analysing small data sets, as these may introduce additional bias and overfitting.

\section{SPORTS INJURIES ARE COMPLEX AND CONTEXTUAL}

As with most health conditions, it is likely that linear and non-linear complex interactions underpin most sports injuries. ${ }^{307172}$ A complex systems approach to sports injuries tries to understand how relationships between the multitude of direct and indirect risk factors result in different paths to being injured. ${ }^{30} 7374$ Further, athletes act within an ecological context where other determinants of risk may be important to take into account. For instance, the finding that the quality of communication between medical staff and team managers in professional soccer clubs was correlated with injury rates expands the understanding of injury mechanisms because failed communication could lead to inappropriate workloads for some athletes. ${ }^{7576}$ The outcomes of studies performed in the ecological context can immediately be used for sports safety promotion interventions and programmes. ${ }^{77}$ To further improve consistency and relevance in recommendations, research approaches that include complex systems models or are ecological are needed to effectively engage stakeholders and qualitatively derive relevant questions to measure quantitatively. 
NEED FOR MULTIDISCIPLINARY TEAMS AND COLLABORATIONS

The presentations and discussions at the MMETHODS MATTER Meeting from various methodology-oriented peers were sometimes contentious but occurred in a relaxed and friendly atmosphere, where open critique was encouraged. To reduce the risk of having the use of statistical techniques in sports injury research referred to as a scandal, ${ }^{3}$ we discussed the next steps. Here are three considerations regarding multidisciplinary collaborations:

- Collaboration is key to bridging gaps between statisticians, researchers and clinical content experts. Developing objectives, design, data acquisition, analyses, interpretation and dissemination in the most appropriate implementation context requires collaborative approaches.

- Different presentations of the same research project to different statisticians, data scientists or injury methodologists will often be met with different recommendations regarding methods.

- Researchers must collaborate more with the statistical community and invest in statistical education in our field (eg, multicentre and interdisciplinary collaborations, reviewer training, online opportunities, trainee exchanges, guidelines, methodological content in meetings).

The next steps in collaboration include ongoing contribution to educational editorials and reviews to accompany those previously published in Journal of Orthopaedic \& Sports Physical Therapy, British Journal of Sports Medicine and other journals. ${ }^{1} 163236444578-84$

\section{CONCLUSION}

The general sentiment at the METHODS MATTER Meeting was that defining sports injury depends on the research question and context. It is essential that researchers are explicit about the goal of any research effort (eg, description, prediction and causal inference) and that they use frameworks to illustrate assumptions underpinning the analytical strategy. Modelling of complex systems was brought forward to illustrate how the description of interaction between risk factors can be an alternative to identifying isolated risk factors.

Investigating changes in exposure status over time is important when analysing sports injury aetiology, even though analysing recurrent injury, subsequent injury or injury exacerbation remains challenging. Finally, the choice of statistical model should consider the research question, injury measure (eg, prevalence, incidence), type of injury data (categorical or continuous) and study design. The view at the meeting was that multidisciplinary collaboration will be the cornerstone for future highquality sports injury science. Working beyond professional silos in a diverse, multidisciplinary team benefits the research process. It promotes better research questions, more appropriate study design and more rigorous statistical analysis. Collaboration also promotes dissemination of study results-a step towards implementation!

\section{Author affiliations}

${ }^{1}$ Department of Public Health, Section for Sports Science, Aarhus University, Aarhus, Denmark

${ }^{2}$ Research Unit for General Practice, Aarhus, Denmark ${ }^{3}$ Centre for Clinical Epidemiology, Lady Davis Institute for Medical Research, Jewish General Hospital, McGill University, Montreal, Quebec, Canada

${ }^{4}$ Sport and Physical Activity Studies Centre (CEEAF), Faculty of Medicine, University of Vic-Central University of Catalonia (UVic-UCC), Barcelona, Spain

${ }^{5}$ Medical Department, Futbol Club Barcelona, Barça

Innovation Hub, Barcelona, Spain

${ }^{6}$ Community Health Sciences, University of Calgary, Calgary, Alberta, Canada

${ }^{7}$ Department of Sports Science and Clinica

Biomechanics, University of Southern Denmark, Odense, Denmark

${ }^{8}$ Amsterdam Collaboration on Health and Safety in Sports, Department of Public and Occupational Health, Amsterdam UMC, Vrije Universiteit Amsterdam, Amsterdam Movement Sciences, Amsterdam, The Netherlands

${ }^{9}$ Sports Physical Therapy Department, Minas Tenis

Clube, Belo Horizonte, Brazil

${ }^{10}$ Physical Therapy, Centro Universitário UniBH, Belo Horizonte, Brazil

${ }^{11}$ Department of Health Promotion, Norwegian Institute of Public Health, Bergen, Norway

${ }^{12}$ Oslo Sports Trauma Research Center, Norwegian

School of Sport Sciences, Department of Sports Medicine, Oslo, Norway

${ }^{13}$ Department of Regional Health Research, University of Southern Denmark, Odense, Denmark

${ }^{14}$ The Orthopedic department, Hospital of Southwestern Jutland, Esbjerg, Denmark

${ }^{15}$ Medical and Scientific Department, Internationa

Olympic Committee, Lausanne, Switzerland

${ }^{16}$ Health and Society, Linköping University, Linköping, Sweden

${ }^{17}$ Kinesiology, University of Calgary, Calgary, Alberta, Canada

${ }^{18}$ Department of Medical and Health Sciences,

Linköping University, Linköping, Sweden

${ }^{19}$ Aspetar Orthopaedic and Sports Medicine Hospital, Doha, Qatar

${ }^{20}$ Department of Behavioural Sciences and Learning, Linköping University, Linköping, Sweden

${ }^{21}$ High Performance Unit, Irish Rugby Football Union, Dublin, Ireland

${ }^{22}$ Section Sports Medicine, Faculty of Health Science, University of Pretoria, Pretoria, South Africa

${ }^{23}$ Medical Department, Royal Netherlands Lawn Tennis Association, Amstelveen, The Netherlands
${ }^{24}$ School of Public Health, University of Sydney, Sydney, New South Wales, Australia

${ }^{25}$ University College London, London, UK

${ }^{26}$ Community Health Sciences, Cumming School of Medicine, University of Calgary, Calgary, Alberta, Canada

${ }^{27}$ Department of Family Practice, The University of British Columbia, Vancouver, British Columbia, Canada

${ }^{28}$ British Journal of Sports Medicine, London, United Kingdom

${ }^{29}$ Division of Physiotherapy, Linköping University, Linköping, Sweden

${ }^{30}$ Division of Physiotherapy, Department of

Neurobiology, Karolinska Institute, Stockholm, Sweden

Correction notice This article has been corrected since it published Online First. Affiliation 21 has been updated.

Twitter Rasmus Oestergaard Nielsen @RUNSAFE Rasmus, Marti Casals @CasalsTMarti, Merete Møller@Merete_Moller, Natália Franco Netto Bittencourt @bittencourt_nfn, Benjamin Clarsen @benclarsen, Torbjørn Soligard @TSoligard,

Carolyn Emery @CarolynAEmery, Jenny Jacobsson @Jenny_Jacobsson, Rod Whiteley @RodWhiteley, Nicol van Dyk @NicolvanDyk, Babette M Pluim @docpluim, Emmanuel Stamatakis @M_Stamatakis, Clare LArdern @clare_ardern and Evert Verhagen @Evertverhagen

Acknowledgements BJSM provided an unrestricted grant for the event that was used to offset hotel meeting room rental and meal costs at the event in Copenhagen.

Contributors RON and EV led the process of drafting the manuscript. Six sections were drafted: $B C, R B$ and CLA drafted the "No universal sports injury definition is necessary" section. CE, NW, AN-A, LP-D and MC drafted the "Which statistical approach should I choose?" section. EV, NFNB, CSB, TT and RW drafted the "Sports injuries are complex and contextual" section. MWF, NvD, JJ and MM drafted the "Analysing longitudinal data" section. NvD, TS, $E V$, ÖD and IS drafted the "Dealing with recurrent or subsequent injury" section. LP-D, KMK, IS, NW, RB and ES drafted the sections "Be explicit about the goal of your research: are you describing, predicting or drawing a causal inference" and "Frameworks can guide researchers". All authors drafted the "Need for multidisciplinary teams and collaborations" section. The content of these sections was merged by $\mathrm{EV}$ and RON. All authors contributed with important intellectual content.

Funding The authors have not declared a specific grant for this research from any funding agency in the public, commercial or not-for-profit sectors.

Competing interests KMK is Editor in Chief, British Journal of Sports Medicine and CLA is Editor in Chief, Journal of Orthopaedic \& Sports Physical Therapy.

Patient consent for publication Not required.

Provenance and peer review Not commissioned; externally peer reviewed.

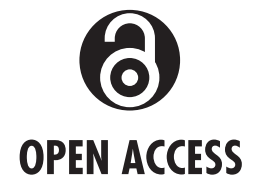

Open access This is an open access article distributed in accordance with the Creative Commons Attribution Non Commercial (CC BY-NC 4.0) license, which permits others to distribute, remix, adapt, build upon this work non-commercially, and license their derivative works on different terms, provided the original work is properly cited, appropriate credit is given, any changes made 
indicated, and the use is non-commercial. See: http:// creativecommons.org/licenses/by-nc/4.0/.

(c) Author(s) (or their employer(s)) 2020. Re-use permitted under CC BY-NC. No commercial re-use. See rights and permissions. Published by BMJ.

- Additional material is published online only. To view please visit the journal online (http://dx.doi.org/ 10.1136/bjsports-2019-101323)

\section{Check for updates}

To cite Nielsen RO, Shrier I, Casals M, et al. Br J Sports Med 2020;54:941-947.

Accepted 19 March 2020

Published Online First 4 May 2020

Br J Sports Med 2020;54:941-947.

doi:10.1136/bjsports-2019-101323

\section{ORCID iDs}

Rasmus Oestergaard Nielsen http://orcid.org/00000001-5757-1806

Marti Casals http://orcid.org/0000-0002-1775-8331

Merete Møller http://orcid.org/0000-0001-7514-0399

Benjamin Clarsen http://orcid.org/0000-0003-37138938

Torbjørn Soligard http://orcid.org/0000-0001-88634574

Toomas Timpka http://orcid.org/0000-0001-6049-5402 Carolyn Emery http://orcid.org/0000-0002-9499-6691 Jenny Jacobsson http://orcid.org/0000-0002-15511722

Rod Whiteley http://orcid.org/0000-0002-1452-6228 Orjan Dahlstrom http://orcid.org/0000-0002-39550443

Emmanuel Stamatakis http://orcid.org/0000-00017323-3225

Karim M Khan http://orcid.org/0000-0002-9976-0258 Clare L Ardern http://orcid.org/0000-0001-8102-3631 Evert Verhagen http://orcid.org/0000-0001-9227-8234

\section{REFERENCES}

1 Verhagen E, Stovitz SD, Mansournia MA, et al. BJSM educational editorials: methods matter. Br J Sports Med 2018;52:1159-60.

2 Altman DG. Statistical reviewing for medical journals. Stat Med 1998;17:2661-74.

3 Altman DG. The scandal of poor medical research. BMJ 1994;308:283-4.

4 Orchard JW, Newman D, Stretch R, et al. Methods for injury surveillance in international cricket. Br J Sports Med 2005;39:e22.

5 Fuller CW, Ekstrand J, Junge A, et al. Consensus statement on injury definitions and data collection procedures in studies of football (soccer) injuries. $\mathrm{Br} \mathrm{J}$ Sports Med 2006:40:193-201.

6 Fuller CW, Molloy MG, Bagate C, et al. Consensus statement on injury definitions and data collection procedures for studies of injuries in rugby union. $\mathrm{Br} \mathrm{J}$ Sports Med 2007;41:328-31.

7 King DA, Gabbett TJ, Gissane C, et al. Epidemiological studies of injuries in rugby league: suggestions for definitions, data collection and reporting methods. J Sci Med Sport 2009;12:12-19.

8 Pluim BM, Fuller CW, Batt ME, et al. Consensus statement on epidemiological studies of medical conditions in tennis, April 2009. Br J Sports Med 2009:43:893-7.

9 Turner M, Fuller CW, Egan D, et al. European consensus on epidemiological studies of injuries in the thoroughbred horse racing industry. Br J Sports Med 2012:46:704-8.

10 Timpka T, Alonso J-M, Jacobsson J, et al. Injury and illness definitions and data collection procedures for use in epidemiological studies in athletics (track and field): consensus statement. Br J Sports Med 2014:48:483-90.

11 Mountjoy M, Junge A, Alonso JM, et al. Consensus statement on the methodology of injury and illness surveillance in FINA (aquatic sports). Br J Sports Med 2016:50:590-6.

12 Orchard JW, Ranson C, Olivier B, et al. International consensus statement on injury surveillance in cricket: a 2016 update. Br J Sports Med 2016;50:1245-51.

13 Timpka T, Jacobsson J, Bickenbach J, et al. What is a sports injury? Sports Med 2014;44:423-8.

14 Clarsen B, Bahr R. Matching the choice of injury/illness definition to study setting, purpose and design: one size does not fit all! Br J Sports Med 2014;48:510-2.

15 Finch CF. An overview of some definitional issues for sports injury surveillance. Sports Med 1997;24:157-63.

16 Nielsen RO, Debes-Kristensen K, Hulme A, et al. Are prevalence measures better than incidence measures in sports injury research? Br J Sports Med 2019:53:396-7.

17 Bahr R, Clarsen B, Ekstrand J. Why we should focus on the burden of injuries and illnesses, not just their incidence. Br J Sports Med 2018:52:1018-21.

18 Fuller CW, Risk I. Injury risk (burden), risk matrices and risk contours in team sports: a review of principles, practices and problems. Sports Med 2018:48:1597-606.

19 Hulin BT. The never-ending search for the perfect acute:chronic workload ratio: what role injury definition? Br J Sports Med 2017;51:991-2.

20 Bahr R. No injuries, but plenty of pain? On the methodology for recording overuse symptoms in sports. Br J Sports Med 2009;43:966-72.

21 Clarsen B, Myklebust G, Bahr R. Development and validation of a new method for the registration of overuse injuries in sports injury epidemiology: the Oslo Sports Trauma Research Centre (OSTRC) overuse injury questionnaire. Br J Sports Med 2013:47:495-502.

22 Hernán MA. The C-word: scientific euphemisms do not improve causal inference from observational data. Am I Public Health 2018;108:616-9.

23 Hernán MA, Hsu J, Healy B. A second chance to get causal inference right: a classification of data science tasks. Chance 2019;32:42-9.

24 Moons KGM, Royston P, Vergouwe Y, et al. Prognosis and prognostic research: what, why, and how? BMJ 2009:338:b375.

25 Shmueli G. To explain or to predict? Statist Sci 2010:25:289-310.

26 Smoliga JM, Zavorsky GS. Team Logo predicts concussion risk: lessons in protecting a vulnerable sports community from misconceived, but highly publicized epidemiologic research. Epidemiology 2017;28:753-7.

27 Meeuwisse WH, Tyreman H, Hagel B, et al. A dynamic model of etiology in sport injury: the recursive nature of risk and causation. Clin J Sport Med 2007:17:215-9.

28 Bahr R, Krosshaug T. Understanding injury mechanisms: a key component of preventing injuries in sport. Br J Sports Med 2005;39:324-9.

29 Hreljac A. Etiology, prevention, and early intervention of overuse injuries in runners: a biomechanical perspective. Phys Med Rehabil Clin N Am 2005:16:651-67.

30 Bittencourt NFN, Meeuwisse WH, Mendonça LD, et al. Complex systems approach for sports injuries: moving from risk factor identification to injury pattern recognition: narrative review and new concept. $\mathrm{Br} J$ Sports Med 2016;50:1309-14.

31 Windt J, Gabbett TJ. How do training and competition workloads relate to injury? The workload-injury aetiology model. Br J Sports Med 2017;51:428-35.

32 Nielsen RO, Bertelsen ML, Møller M, et al. Training load and structure-specific load: applications for sport injury causality and data analyses. Br J Sports Med 2018;52:1016-7
33 Bertelsen ML, Hulme A, Petersen J, et al. A framework for the etiology of running-related injuries. Scand J Med Sci Sports 2017;27:1170-80.

34 Meeuwisse WH, Tyreman $\mathrm{H}$, Hagel B, et al. A dynamic model of etiology in sport injury: the recursive nature of risk and causation. Clin J Sport Med 2007; 17:215-9.

35 Shrier I, Platt RW. Reducing bias through directed acyclic graphs. BMC Med Res Methodo 2008;8:70-2288.

36 Stovitz SD, Verhagen E, Shrier I. Distinguishing between causal and non-causal associations: mplications for sports medicine clinicians. Br J Sports Med 2019;53:398-9.

37 Mansournia MA, Etminan M, Danaei G, et al. Handling time varying confounding in observational research. BMJ 2017:359:j4587.

38 Shakiba M, Mansournia MA, Salari A, et al. Accounting for time-varying confounding in the relation between obesity and coronary heart disease: analysis with G-estimation, the Atherosclerosis risk in communities (ARIC) study. Am J Epidemiol 2018;187:1318-26.

39 Naimi Al, Cole SR, Kennedy EH. An introduction to G methods. Int J Epidemio/ 2017:46:756-62.

40 Mansournia MA, Altman DG. Inverse probability weighting. BMJ 2016:352:i189.

41 Gunn JE, Shah SN. Big data and opportunities for injury surveillance. Inj Prev 2016;22:i3-5.

42 Casals M, Finch CF. Sports biostatistician: a critical member of all sports science and medicine teams for injury prevention. Inj Prev 2017;23:423-7.

43 Cronbach LJ, Furby L. How we should measure "change": Or should we? Psychol Bull 1970;74:68-80.

44 Nielsen RO, Bertelsen ML, Ramskov D, et al. Time-toevent analysis for sports injury research. Part 2: Timevarying outcomes. Br J Sports Med 2019:53:70-8.

45 Nielsen RO, Bertelsen ML, Ramskov D, et al. Time-toevent analysis for sports injury research. Part 1: Timevarying exposures. Br J Sports Med 2019;53:61-8.

46 Windt J, Ardern CL, Gabbett TJ, et al. Getting the most out of intensive longitudinal data: a methodological review of workload-injury studies. BMJ Open 2018:8:e022626.

47 Richardson TS, Rotnitzky A. Causal etiology of the research of James M. Robins. Stat SCi 2014;29:459-84.

48 Zhou Y, McArdle JJ. Rationale and applications of survival tree and survival ensemble methods. Psychometrika 2015:80:811-33.

49 Chipman HA, George El, McCulloch RE. Bart: Bayesian additive regression trees. Ann App/ Stat 2010;4:266-98

50 Burton P, Gurrin L, Sly P. Extending the simple linear regression model to account for correlated responses: an introduction to generalized estimating equations and multi-level mixed modelling. Stat Med 1998;17:1261-91

51 Claudino JG, Capanema DdeO, de Souza TV, et al. Current approaches to the use of artificial intelligence for injury risk assessment and performance prediction in team sports: a systematic review. Sports Med Open 2019;5:28

52 James $G$, Witten D, Hastie T, et al. An introduction to statistical learning: with applications in R. New York: Springer, 2013.

53 Yergens DW, Dutton DJ, Patten SB. An overview of the statistical methods reported by studies using the Canadian Community Health Survey. BMC Med Res Methodol 2014:14:15.

54 Casals M, Langohr K, Carrasco JL, et al. Parameter estimation of Poisson generalized linear mixed models based on three different statistical principles: a simulation study. Sort-Stat Oper Res $T$ 2015:39:281-307.

55 Bolker BM, Brooks ME, Clark CJ, et al. Generalized linear mixed models: a practical guide for ecology and evolution. Trends Ecol Evol 2009;24:127-35. 
56 Booth JG, Casella G, Friedl H, et al. Negative binomial loglinear mixed models. Stat Modelling 2003;3:179-91.

57 Andersen PK, Keiding N. Interpretability and importance of functionals in competing risks and multistate models. Stat Med 2012;31:1074-88.

58 Ullah S, Gabbett TJ, Finch CF. Statistical modelling for recurrent events: an application to sports injuries. $\mathrm{Br} J$ Sports Med 2014;48:1287-93.

59 Olesen AV, Parner ET. Correcting for selection using frailty models. Stat Med 2006;25:1672-84.

60 Huang $X$, Wolfe RA. A frailty model for informative censoring. Biometrics 2002;58:510-20.

61 Shrier I, Steele RJ, Zhao M, et al. A multistate framework for the analysis of subsequent injury in sport (M-FASIS). Scand I Med Sci Sports 2016:26:128-39.

62 Johansen B, Wedderkopp N. Comparison between data obtained through real-time data capture by SMS and a retrospective telephone interview. Chiropr Osteopat 2010;18:10.

63 Chéron C, Leboeuf-Yde C, Le Scanff C, et al. Leisure-time sport and overuse injuries of extremities in children age $6-13$, a 2.5 years prospective cohort study: the CHAMPS-study DK. BMJ Open 2017:7:e012606

64 Junge T, Runge L, Juul-Kristensen B, et al. Risk factors for knee injuries in children 8 to 15 years: the CHAMPS study DK. Med Sci Sports Exerc 2016;48:655-62.

65 Jespersen E, Holst R, Franz C, et al. Overuse and traumatic extremity injuries in schoolchildren surveyed with weekly text messages over 2.5 years. Scand J Med Sci Sports 2014;24:807-13.
66 Jespersen E, Holst R, Franz C, et al. Seasonal variation in musculoskeletal extremity injuries in school children aged 6-12 followed prospectively over 2.5 years: a cohort study. BMJ Open 2014:4:e004165.

67 Nauta J, Jespersen E, Verhagen E, et al. Upper extremity injuries in Danish children aged 6-12, mechanisms, and risk factors. Scand J Med Sci Sports 2017;27:93-8.

68 Andersen PK, Geskus RB, de Witte T, et al. Competing risks in epidemiology: possibilities and pitfalls. Int $J$ Epidemiol 2012:41:861-70.

69 Putter H, Fiocco M, Geskus RB. Tutorial in biostatistics: competing risks and multi-state models. Stat Med 2007;26:2389-430

70 Satagopan JM, Ben-Porat L, Berwick M, et al. A note on competing risks in survival data analysis. $\mathrm{Br} J$ Cancer 2004:91:1229-35.

71 Mendiguchia J, Alentorn-Geli E, Brughelli M. Hamstring strain injuries: are we heading in the right direction? Br J Sports Med 2012;46:81-5.

72 Quatman CE, Quatman CC, Hewett TE. Prediction and prevention of musculoskeletal injury: a paradigm shift in methodology. Br J Sports Med 2009;43:1100-7.

73 Philippe P, Mansi O. Nonlinearity in the epidemiology of complex health and disease processes. Theor Med Bioeth 1998;19:591-607.

74 Hulme A, Finch CF. From monocausality to systems thinking: a complementary and alternative conceptual approach for better understanding the development and prevention of sports injury. Inj Epidemiol 2015;2:31

75 Ekstrand J, Lundqvist D, Davison $\mathrm{M}$, et al. Communication quality between the medical team and the head coach/manager is associated with injury burden and player availability in elite football clubs. $\mathrm{Br}$ J Sports Med 2019;53:304-8.

76 Pol R, Hristovski R, Medina D, et al. From microscopic to macroscopic sports injuries. applying the complex dynamic systems approach to sports medicine: a narrative review. Br J Sports Med 2019;53:1214-20.

77 Timpka T, Ekstrand J, Svanström L. From sports injury prevention to safety promotion in sports. Sports Med 2006;36:733-45.

78 Hjerrild M, Videbaek S, Theisen D, et al. How (not) to interpret a non-causal association in sports injury science. Phys Ther Sport 2018;32:121-5.

79 Hulme A, Thompson J, Nielsen RO, et al. Towards a complex systems approach in sports injury research: simulating running-related injury development with agent-based modelling. Br J Sports Med 2019:53:569

80 Nielsen RO, Chapman CM, Louis WR, et al. Seven SINS when interpreting statistics in sports injury science. $\mathrm{Br}$ I Sports Med 2018;52:1410-2.

81 Nielsen RO, Bertelsen ML, Verhagen E, et al. When is a study result important for athletes, clinicians and team coaches/staff? Br J Sports Med 2017;51:1454-5.

82 Nielsen Rasmus Østergaard, Malisoux L, Møller M, et al. Shedding light on the etiology of sports injuries: a look behind the scenes of time-to-event analyses. J Orthop Sports Phys Ther 2016;46:300-11.

83 Stovitz SD, Verhagen E, Shrier I. Misinterpretations of the ' $p$ value': a brief primer for academic sports medicine. Br J Sports Med 2017;51:1176-7.

84 Shrier I. Understanding causal inference: the future direction in sports injury prevention. Clin I Sport Med 2007:17:220-4. 